\title{
BMJ Open Active and passive work breaks during simulated laparoscopy among laparoscopic surgeons: study protocol for a controlled, randomised cross-over laboratory trial
}

\author{
Tessy Luger (10 , ${ }^{1}$ Monika A Rieger, ${ }^{1}$ Rosina Bonsch, ${ }^{1}$ Bernhard Krämer, ${ }^{2}$ \\ Robert Seibt, ${ }^{1}$ Benjamin Steinhilber ${ }^{1}$
}

To cite: Luger T, Rieger MA, Bonsch $\mathrm{R}$, et al. Active and passive work breaks during simulated laparoscopy among laparoscopic surgeons: study protocol for a controlled, randomised cross-over laboratory trial. BMJ Open 2020;10:e038952. doi:10.1136/ bmjopen-2020-038952

- Prepublication history and additional material for this paper is available online. To view these files, please visit the journal online (http://dx.doi.org/10. 1136/bmjopen-2020-038952)

Received 30 March 2020 Revised 10 October 2020 Accepted 24 October 2020

Check for updates

(c) Author(s) (or their employer(s)) 2020. Re-use permitted under CC BY-NC. No commercial re-use. See rights and permissions. Published by BMJ.

${ }^{1}$ Institute of Occupational and Social Medicine and Health Services Research, University Hospital of Tübingen, Tübingen, Germany

${ }^{2}$ Department of Gynecology, University Hospital of Tübingen, Tübingen, Germany

\section{Correspondence to}

Dr Tessy Luger;

tessy.luger@med.uni-tuebingen. de

\section{ABSTRACT}

Introduction Laparoscopy has partially replaced open surgery due to the lower infection rate for the patient and hence better and shorter recovery. However, the surgeon's physical load is higher due to longer duration static and awkward body postures, increasing the risk for developing work-related musculoskeletal disorders. Interventions of an organisational nature are work breaks, being either passive or active. The primary objectives of this study are to determine whether passive and active work breaks lead to less discomfort than no work breaks and whether active work breaks lead to less discomfort than passive work breaks.

Methods and analysis A controlled, randomised cross-over trial will be performed in the laboratory, of which its protocol is described here according to the Standard Protocol Items: Recommendations for Interventional Trials (SPIRIT) 2013 Statement. Recruitment of 21 laparoscopic surgeons started in April 2019 and the study is ongoing. The participating surgeons will perform three 1.5 hour experimental conditions, one without work breaks, one with 2.5 min passive work breaks including rest, and one with $2.5 \mathrm{~min}$ active work breaks including mobility and stretching exercises. The work breaks will be taken after 30 and 60 min of work. During the experiments, outcomes will be recorded. The primary outcome is rating of perceived discomfort measured on an 11-point numeric rating scale. The secondary outcomes are performance, muscle activity of selected muscles, upper body angles, heart rate, workload and subjective evaluation of both interventions. The collected data will be tested using a one-way or two-factorial repeated-measures analysis of variance. Ethics and dissemination Ethical approval of the study protocol was received by the local medical ethical committee of the University of Tübingen in February 2019 (no 618/2018B02). The results of this study will be presented at national and international conferences, submitted for publications in peer-reviewed journals and serve as the starting point for a feasibility study.

Trial registration number NCT03715816.

\section{INTRODUCTION}

\section{Background}

The first known laparoscopic intervention in humans was performed in 1947 in France. ${ }^{1}$

\section{Strengths and limitations of this study}

- The described study will be among the earliest comparing active and passive intraoperative work breaks against no breaks in a simulated laparoscopic setting, applying a controlled, randomised crossover design.

- The study cannot be blinded, that is, the researchers know to which experimental condition (control or intervention) the participant is randomly allocated and the participants know after start of the measurement to which experimental condition (control or intervention) they are exposed.

- The primary outcome is perceived rating of discomfort, which will provide valuable information whether the participating surgeons experience the implemented work breaks as promising or not.

- Activity of muscles involved in laparoscopic work, upper body posture and heart rate are secondary outcomes for this study that are objectively measured and may support the results of the primary outcome.

- The trial is not designed to detect differences in secondary outcomes or subgroups, which means that these will be considered following an exploratory approach and be hypothesis generating

This technique, also known as minimally invasive surgery (MIS), has partially replaced open surgery because it reduces patient's postsurgical pain due to the smaller incisions and is hence characterised by lower infection rates and shorter recovery times. ${ }^{2-4}$ Besides the sources of psychological stress that surgeons have to deal with, such as work pressure and dealing with the patient's well-being, ${ }^{5}$ MIS additionally creates increased exposure to sources of physical stress, such as static loading and awkward body postures. ${ }^{67}$ These external, physical stressors increase the physical strain on the surgeon and may, consequently, 
increase the risk of developing work-related musculoskeletal disorders (WRMSD). ${ }^{89}$ According to a recent review of the literature, prevalence rates of WRMSD among endoscopists, urologists, gynaecologists, otolaryngologists and ophthalmologists performing MIS range between $43 \%$ and $88 \% .^{10}$ The most affected body sites are the neck, back and shoulders. ${ }^{11} 12$

Two types of interventions addressing the working conditions could potentially be applied to counteract the prevalence of WRMSD in the surgical environment: interventions related to workplace factors and interventions related to work-organisational factors. ${ }^{13}$ A first example of improving workplace factors is to use ergonomically designed surgical equipment, since many different instrument handles are available. ${ }^{1415}$ Among others, two studies have evaluated the use of rotatable handle pieces to decrease the time spent in awkward hand, arm and wrist postures. ${ }^{16}$ Both studies concluded that wrist postures were less extreme in case the instruments with rotatable handle piece were used. An ergonomic articulating laparoscopic grasping tool has been evaluated and was preferred over a conventional laparoscopic grasping tool because the participating surgeons experienced less hand pain, stiffness and numbness with the articulating tool. ${ }^{18}$ Another example of improving workplace factors is the implementation of ergonomic supports that could reduce the amount of physical stress in the body. ${ }^{19}$ A laboratory study that evaluated an arm support system showed that it did not change the shoulder, arm and hand posture of the surgeon. ${ }^{20}$ Another study evaluated a body support and found promising results by concluding from subjective reports that the body support, which was a type of stand support, could be an effective way to reduce perceived discomfort. ${ }^{21}$ A more recent study developed a surgical knee rest to decrease stress placed on the lower extremities during surgery in a standing position and found that the muscle activity of the gastrocnemius decreased. ${ }^{22}$

The most well-known example of an intervention that relates to work-organisational factors is the implementation of load alternating rest periods or breaks. A strong advantage of implementing work breaks is that not only the surgeon may benefit, but also other medical personnel involved in the surgical procedure. A recent systematic review, however, found solely randomised controlled trials performed among workers using visual display units without any evidence for positive associations of different types, durations and frequencies of work breaks on musculoskeletal outcomes. ${ }^{23}$ Taking breaks during surgeries does not appear to be a common habit, according to a recent survey study, within which only $4.8 \%$ of the laparoscopic surgeons indicated experiencing scheduled intraoperative breaks. ${ }^{24}{ }^{25}$ However, several studies performed in the surgical field that were not randomised controlled trials actually have shown promising results, of which the most important are no prolonged surgery duration, ${ }^{26} 27$ reduced discomfort mainly at the shoulders, neck, hands and back, ${ }^{27-29}$ and reduced error rate. ${ }^{26}{ }^{28}$ Engelmann et $a l^{26}$ investigated $5 \mathrm{~min}$ passive work breaks, whereas
Dorion and Darveau, ${ }^{28}$ Hallbeck, et $a l^{29}$ and Park et $a l^{27}$ investigated active work breaks containing stretching exercises for a $20 \mathrm{~s}^{28}$ or $1.5 \mathrm{~min}^{2729}$ duration every $20-40$ min working period. Two more recent studies focused on the development of either an optimised active work-break structure $^{30}$ or a web-based application that video guide the surgeon to perform some stretch work breaks. ${ }^{31}$

\section{Objectives}

The primary aims of this study are to investigate during 1.5 hour simulated laparoscopic surgery activities whether:

- ... passive work breaks alleviate discomfort when compared with no work breaks;

- ... active work breaks alleviate discomfort when compared with no work breaks;

- ... active work breaks alleviate discomfort more than passive work breaks.

The secondary aims of this study are to investigate during 1.5 hour simulated laparoscopic surgery activities whether:

- ... passive work breaks when compared with no work breaks...;

- ... active work breaks when compared with no work breaks...;

- ...active work breaks when compared with passive work breaks...;

...lead to changes in performance, static muscular activity, median muscular activity, peak muscular activity, muscular fatigue, upper body postures, heart rate (HR), heart rate variability (HRV) and perceived workload. Additionally, feedback about some implementation aspects of both work break interventions will be evaluated, that is, content, frequency, duration, performance and concentration.

\section{METHODS AND ANALYSIS}

The protocol of the here described controlled, randomised cross-over trial is based on the guided checklist provided by the Standard Protocol Items: Recommendations for Interventional Trials (SPIRIT) 2013 Statement. ${ }^{32} 33$ The study protocol has been registered at clinicaltrials.gov (NCT03715816).

\section{Study design}

Two different work break interventions, that is, a passive and active work break intervention (for more information, see Work break intervention), will be compared with the control condition, within which no work break intervention will be implemented. All three scenarios will be investigated during simulated laparoscopy in a controlled, randomised cross-over trial. We have chosen that each subject acts as his own control to keep the necessary sample size to a minimum. The study will take place in the laboratory and will not be blinded, that is, the researcher will not be blinded to the intervention to which the participant is randomly allocated and the participant will not be blinded to the intervention. 


\section{Consent of study participants}

A written informed consent and written data privacy consent are necessary prior to study enrolment, which are obtained by the researcher who is leading the familiarisation trial. The eligible participant has the ability to have an informed discussion with the researcher about the trial and gather additional information if desired. A template informed consent form and data privacy consent form can be found translated from German in online supplemental material 1 and 2.

\section{Recruitment and eligibility criteria}

Due to a close collaboration with the Department of Gynaecology (DOG) of the University of Tübingen (UKT, Germany), study participants, that is, laparoscopic surgeons, are recruited by means of direct advertisement and internal email announcements. During the first visit at the laboratory, the participants have the study explained to them by the researcher, after which they will be examined whether they fulfil the inclusion and exclusion criteria (see below) for study participation. When they are willing to voluntarily participate in the study, they have to sign informed and data protection consents (see online supplemental material 1 and 2).

\section{Inclusion criteria}

- Aged 18 years or older at the time of participation.

- Sufficient understanding of the German language.

- Experience with (simulated) laparoscopic activities.

- Ability to perform the peg transfer task within $3 \mathrm{~min}$, which is a standardised task and part of the Fundamentals of Laparoscopic Surgery (FLS) as introduced by the Society of American Gastrointestinal Endoscopic Surgeons (SAGES). ${ }^{34}$ This task tests eye-hand coordination, ambidexterity and depth perception, by grasping six objects with the left hand, transferring each object to the right hand and placing each object on the right side of the pegboard (for more information, see Experimental procedure).

\section{Exclusion criteria}

- Less than 18 years old at the time of participation.

- Not being able to perform the standardised peg transfer task ${ }^{34}$ within 3 min.

- Having one of the following (anamnestic) disorders, disabilities or conditions: sensory disturbances; vascular diseases; cardiovascular diseases; muscular disorders; heart disease (e.g., pacemaker); severe muscular contractions; acute pain; diabetes mellitus; Parkinson's disease; symptomatic sensory or motor polyneuropathy; alcohol abuse; severe muscle contractions; under the influence of intoxicants, analgesics or muscle relaxants; symptomatic neurologicalpsychiatric diseases.

- Not being able to complete the examination programme due to language or cognitive obstacles.

- Blood pressure of $\geq 139 / \leq 100 \mathrm{~mm} \mathrm{Hg}$, which may hinder the participant to perform maximal voluntary contractions (MVC) that are necessary for normalisation of the measurement of muscle activity.

\section{Work-break intervention}

Duration, frequency and timing of the intervention

Previous research that was performed in another field of work showed that $30 \mathrm{~s}$ work breaks after $30 \mathrm{~min}$ of work may not be sufficiently long to lead to any effects on perceived discomfort. ${ }^{35}$ More recent studies showed that 1.5, 2 and 5 min work breaks after 20-40 min of surgical work may be effective in reducing perceived discomfort among surgeons. ${ }^{26} 2729$ Based on the positive effects of these studies, the duration of the work breaks that will be implemented in the current study will be $2.5 \mathrm{~min}$ and provided after $30 \mathrm{~min}$ of surgical work, which is a good compromise between previously shown effective pause durations without longer surgeries.

Although previous studies investigated the effect of work breaks within $120,{ }^{2728} 150^{29}$ or 180 min surgery durations, ${ }^{26}$ the current study will implement two 2.5 min work breaks within a 90 min simulated laparoscopic surgery. The reasons for this 90 min laparoscopy duration are the controlled study design, the simulation in the laboratory and the fact that laparoscopic surgeries last on average about 75 min. $^{36}$

\section{Content of the intervention}

The 2.5 min interventions can be offered with different contents and can consequently be considered as passive or active breaks. Both types of work breaks have been investigated in the surgical field of work. In the study of Engelmann et al, ${ }^{26}$ unstructured passive work breaks have been applied, that is, when workers just rest, in line with the definition of Luger et al. ${ }^{23}$ In the current study, the surgeon will undergo a 2.5 min passive work break, that is, the surgeon just rests, while standing and remaining in his position next to the laparoscopic setting, allowing him to lay down the laparoscopic instruments.

The active work breaks are defined according to literature to contain stretching, mobility or relaxing exercises, walks or cognitive tasks. ${ }^{23}$ The studies performed in the surgical field of work that investigated the implementation of active work breaks mainly contained stretching exercises. ${ }^{27-29}$ For the current study, we wanted the exercises to be designed for target body regions within which surgeons regularly report perceived feelings of discomfort, fatigue or pain or even WRMSD and the exercises to focus on (1) posture correction, (2) normalisation of tissue tension and soft-tissue mobility or (3) relaxation. ${ }^{30}$ We aimed to develop an active work break intervention, especially covering the first two aspects of Coleman Wood et $a l^{30}$ that is, posture correction and normalisation of tissue tension and mobility. Based on preliminary results of a survey study among laparoscopic surgeons, the main body regions for which discomfort or complaints were reported were the neck (67\%), shoulders $(65 \%)$ and lower back $(64 \%) .{ }^{24} 25$ In collaboration with a physiotherapist of the UKT, a set of seven different exercises 
was developed, for which standardised instructions were provided of which an audio recording is made (spoken by author BS) that is played back when the participating surgeon has the condition with active work breaks (see online supplemental material 3 for a detailed description of the exercises):

1. Whole-body mobilisation exercise.

2. Hip mobilisation exercise.

3. Lower back stretching exercise.

4. Upper back and shoulder stretching exercise.

5. Shoulder mobilisation exercise.

6. Neck stretching exercise.

7. Neck mobilisation exercise.

8. Whole body mobilisation exercise.

The number of repetitions and the range of motion of each of the exercises were not controlled for since the applied exercises were meant to activate all relevant body locations at very low exercise intensity unlikely to induce adaptations in, for example, muscle strength. ${ }^{37}$ The researcher controlled for the participant performing the exercises during the complete time window given on the standardised audio recording.

\section{Study outcomes}

The demographic and background outcomes will be collected at baseline during the familiarisation trial, whereas the primary and secondary outcomes will be assessed during the laboratory measurements. All outcomes are listed in table 1.

\section{Sample size}

Due to a lack of data from literature, we were not able to estimate the correlation between the three experimental conditions, which is necessary to calculate the sample size for a within-subject design. ${ }^{38}{ }^{39}$ Therefore, we used a conservative approach to determine the sample size based on the formula for the sample size for a betweensubject design (Equation 1). ${ }^{40}$ The required sample size was calculated for the primary outcome, rating of perceived discomfort (RPD). We used Equation 1, ${ }^{40}$ with a level of significance and study power of $5 \%$ and $80 \%$, respectively. The effect sizes and pooled SD were derived from a study that investigated intraoperative $20 \mathrm{~s}$ active work breaks every $20 \mathrm{~min}$ during surgeries lasting at least $120 \mathrm{~min}$ and compared it against no work breaks. ${ }^{28}$ The authors reported findings of the perceived level of discomfort using a $100 \mathrm{~mm}$ visual analogue scale (VAS) from which a general effect size and general pooled SD of 16.8571 and 19.3372 could be calculated, respectively. When directly translated to an 11-point (0 to 10) numeric rating scale (NRS), the effect size and pooled SD would be 1.6857 and 1.9337 , respectively. These numbers result in a required sample size of 21 participants, excluding potential drop-outs

$$
\mathrm{n}=\frac{2 \cdot\left(\mathrm{Z}_{\alpha}+\mathrm{Z}_{1-\beta}\right)^{2} \cdot \sigma^{2}}{\delta^{2}}
$$

Table 1 Collection of study outcomes, divided into primary, secondary and demographic outcomes

\begin{tabular}{|c|c|c|}
\hline Primary outcome & $\begin{array}{l}\text { Secondary } \\
\text { outcomes }\end{array}$ & Demographic outcomes \\
\hline \multirow{11}{*}{$\begin{array}{l}\text { Rating of } \\
\text { perceived } \\
\text { discomfort }\end{array}$} & $\begin{array}{l}\text { Performance hot } \\
\text { wire task * }\end{array}$ & Primary job description \\
\hline & $\begin{array}{l}\text { Performance peg } \\
\text { transfer task * }\end{array}$ & $\begin{array}{l}\text { Total laparoscopic } \\
\text { experience(years) }\end{array}$ \\
\hline & $\begin{array}{l}\text { Static electrical } \\
\text { activity of arm, } \\
\text { shoulder and back } \\
\text { musclest }\end{array}$ & $\begin{array}{l}\text { Total of laparoscopies } \\
\text { carries out to date(\#) }\end{array}$ \\
\hline & $\begin{array}{l}\text { Median electrical } \\
\text { activity of arm, } \\
\text { shoulder and back } \\
\text { musclest }\end{array}$ & $\begin{array}{l}\text { Current average of } \\
\text { laparoscopies/week(\#) }\end{array}$ \\
\hline & $\begin{array}{l}\text { Peak electrical } \\
\text { activity of arm, } \\
\text { shoulder and back } \\
\text { musclest }\end{array}$ & Age \\
\hline & Lumbar lordosis & Gender \\
\hline & Thoracic kyphosis & Body height \\
\hline & Cervical lordosis & Body weight \\
\hline & Heart rate & Smoking status \\
\hline & Workload & Sport hours/week(\#) \\
\hline & $\begin{array}{l}\text { Subjective } \\
\text { evaluation of the } \\
\text { intervention }\end{array}$ & Musculoskeletal status \\
\hline
\end{tabular}

*The hot wire task and peg transfer task will be described in more detail under Methods and analysis $>$ Experimental procedure †The static, median and peak electrical activities of the various muscles will be determined by recording of surface electromyography, which is described in more detail under Methods and analysis >Data collection $>$ Secondary outcomes.

with $n$ the sample size; $Z_{\alpha}$ the constant $z$-value based on the accepted two-sided level of significance or $\alpha$ error (ie, $5 \%$ or 0.05$)$, resulting in a value of $1.96 ; Z_{1-\beta}$ the constant $z$-value based on the chance to miss a real difference (ie, the inverse of the study power of $80 \%$ or 0.80 ), resulting in a value of $0.8416 ; \sigma$ the pooled $\mathrm{SD}$ based on previously reported data (here: 1.9337); the effect size or difference in effect of two interventions based on previously reported data (here active vs no work breaks: 1.6857).

\section{Study duration and participant timeline}

The study is planned to last for a total of one-and-a-half to two calendar years. Study preparation, including ethics approval and pilot testing, lasted about 3 months. Subject recruitment started in March 2019 and, together with data collection, is estimated to last until the summer of 2020.

Study participants are informed to take into account a study-related time commitment of four appointments spread over four different days, including one familiarisation trial (about 1 hour) and three experimental trials (about 2.5 hours; see figure 1). During the familiarisation trial, the participants will go through the active work break script together with the researcher to get familiar with the 


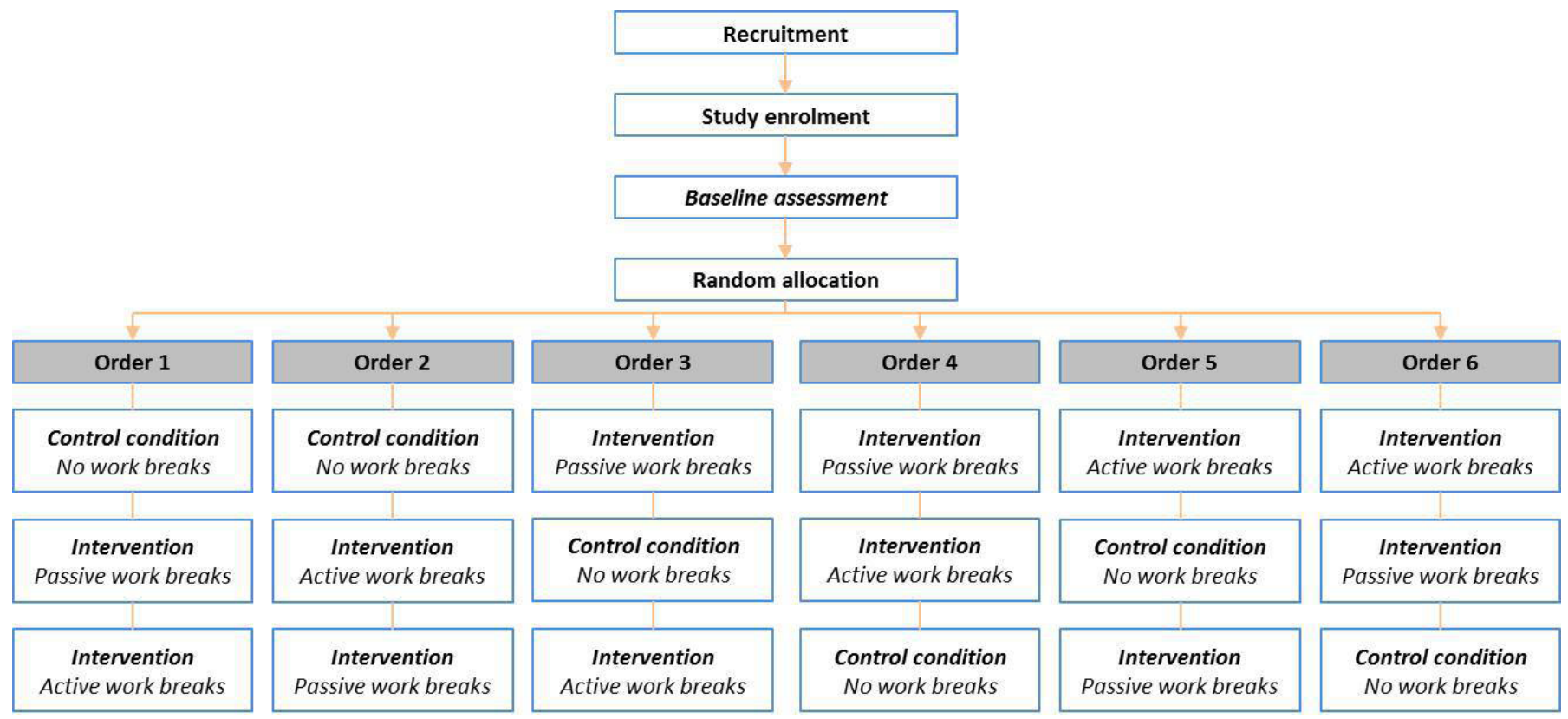

Figure 1 Flow chart displaying the process of the cross-over study. Participants will be randomly allocated by the principal investigator $(\mathrm{TL})$ to one of the six possible orders of the three conditions.

mobility and stretching exercises. The researcher informs the participating surgeon that the goal of the exercises is to perform them during the given time window in a way that it feels comfortable for them, meaning the range of motion and number of repetitions of each exercise are not controlled for. Each participant will receive a small financial compensation after full participation.

\section{Randomisation}

The order of the three conditions will be assigned to the participating surgeon by drawing a lot from a box by the principal investigator (TL). Six different orders of conditions are possible (ABC I ACB | BAC I BCA I CAB | CBA; cf. figure 1) of which the fourfold can be found written on paper in the box.

\section{Experimental procedure}

The 90-minute experiment will consist of tasks with which laparoscopic psychomotor skills will be simulated in a Pelvic Trainer (Szabo, ID Trust Medical, Belgium). The Pelvic Trainer is a validated endoscopic device used by hospitals and universities to train medical students and other staff the laparoscopic tasks without the risk of harming patients. The optics in the Pelvic Trainer, that is, camera with light source (Karl Storz 26003AA HOPKINS II Optik $0^{\circ}$, Karl Storz SE \& Co. KG, Tuttlingen, Germany), will be in a fixed position and connected to a screen in front of the participant to display the task. The light intensity and operation room temperature were randomly measured prior to onset of the study in the operation theatre of the DOG at the UKT, and ranged 5-17Lux (Light Meter, LX-107, Lutron Electronic Enterprise Co., Taipei, Taiwan) and $22.8^{\circ} \mathrm{C}$ to $26.2^{\circ} \mathrm{C}$ (Thermometer, OPUS10 THI, SwiCAL swiss calibration GmbH, Bern, Switzerland), respectively. The laboratory temperature was regulated and ranged between $24^{\circ} \mathrm{C}$ and $26^{\circ} \mathrm{C}$; the light intensity in the room ranged between 5 and $9 \mathrm{Lux}$.

The tasks included in the $90 \mathrm{~min}$ simulations will be described below in more detail. Directly before and after the 90 min simulation, a hot-wire task is executed. This task is performed without time restrictions and therefore not included as part of the 90 min simulation. The simulation itself will consist of three $30 \mathrm{~min}$ blocks, each comprising five different simulated laparoscopic tasks that will be performed in a set order: peg-transfer, pick-and-place, pick-and-tighten, peg-transfer, pick-andthread, pull-and-stick, peg-transfer. These tasks are chosen because they mimic handlings the laparoscopic surgeons perform during their daily operational tasks, including hand-eye coordination, ambidexterity, needle transferring and accuracy. ${ }^{41} \mathrm{~A}$ picture of all six tasks is presented in figure 2 and a schematic time course of the conditions including two work breaks after 30 and $60 \mathrm{~min}$ of simulated laparoscopy is displayed in figure 3 . The active work break will be guided by a standardised audio recording of the exercises (cf. Content of the intervention). A foot pedal is integrated in the pick-and-place and pick-andthread tasks to simulate coagulation, which is an action that occurs in many laparoscopic procedures in the field of gynaecology.

The hot-wire task is performed by the dominant hand, for which the participant has to move a metal ring that is held by a $34 \mathrm{~cm}$ long laparoscopic Maryland bipolar forceps (model no. 20195-225, ERBE Elektromedizin $\mathrm{GmbH}$, Tübingen, Germany) from the right side to the left side of a hot-wire and back. The primary goal is not to touch the hot-wire because that will produce a beeping sound, and the secondary goal is to simultaneously move the ring back and forth along the wire as fast as 


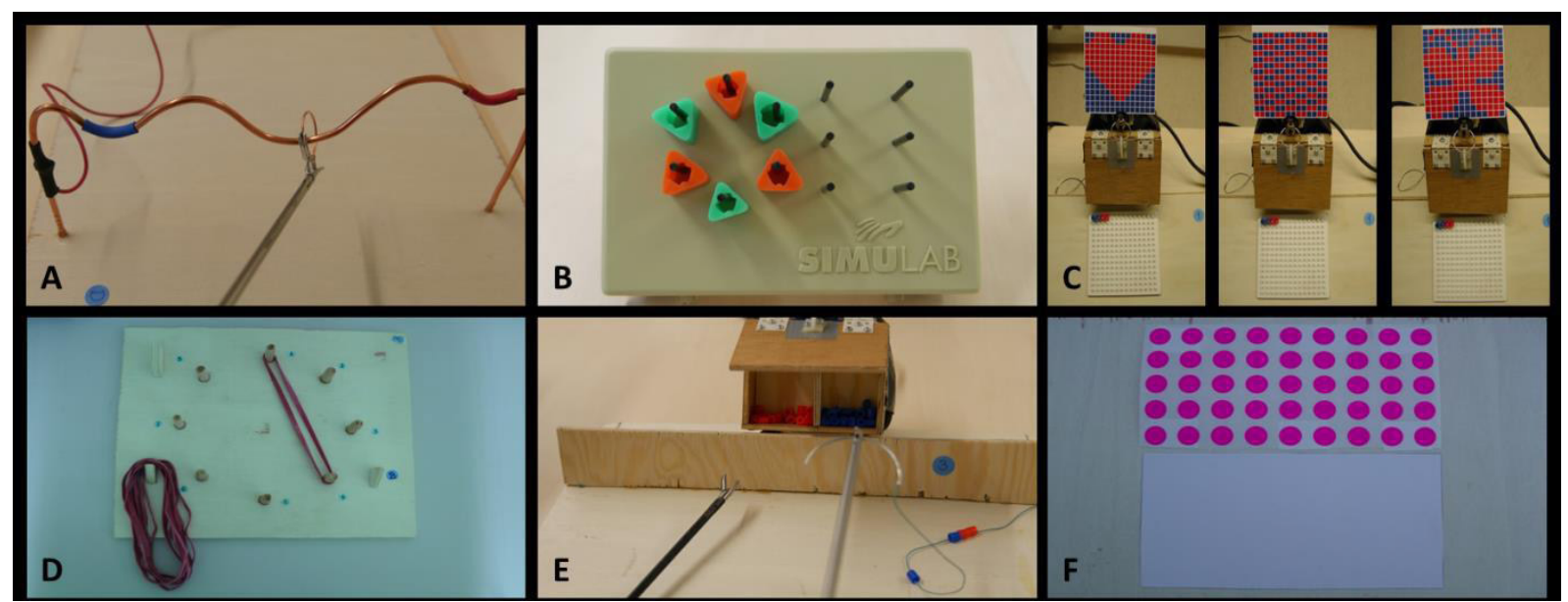

Figure 2 The six tasks performed within the Pelvic Trainer: hot-wire (A), peg-transfer (B), pick-and-place (C), pick-and-tighten (D), pick-and-thread (E), pull-and-stick (F).

possible. The hot-wire is curved in $2 \mathrm{D}$ and is $21.5 \mathrm{~cm}$ long. Performance time of the hot-wire task is tracked using a regular stopwatch (model no WT-035, BASETech, Conrad Electronic SE, Hirschau, Germany) and both trials are recorded using an audio-recording device (Linear PCM Recorder LS-P1, Olympus GmbH, Hamburg, Germany).

The standardised peg-transfer task is performed bimanually with a $33 \mathrm{~cm}$ long forceps with 1:2 teeth (RS225-595, RUDOLF Medical GmbH \& Co. KG, Fridingen, Germany) in the right hand and a $33 \mathrm{~cm}$ long forceps without teeth (33321 KW, KARL STORZ SE \& Co. KG) in the left hand. The participant has to move green and orange triangles from pins oriented in a circle on the left to pins oriented in a rectangular on the right of the peg-transfer-board (Simulab, Seattle, Washington, USA) and back. The task is performed by taking the triangles from the pins on the left with the instrument in the left hand, transferring it to the instrument in the right hand and placing it on the pins on the right. The peg-transfer task is performed for exactly $60 \mathrm{~s}$ and is repeated nine times during each experimental condition. The peg-transfer task is part of the FLS as introduced by the SAGES ${ }^{34}$ and has shown high reliability (intraclass correlation coefficient (ICC) of 0.89 to 0.99 ) and good validity (predictive values above 0.80$).{ }^{42}$

The pick-and-place task is performed bimanually with a $33 \mathrm{~cm}$ long forceps with 1:2 teeth (RS225-595, RUDOLF Medical GmbH \& Co. KG) in the right hand and a $33 \mathrm{~cm}$ long forceps without teeth (33321 KW, KARL STORZ SE \& Co. KG) in the left hand and will last up to $6.75 \mathrm{~min}$. The participant has to take a red or blue bead (diameter $5 \mathrm{~mm}$ ) from a wooded box (length $78.8 \mathrm{~mm}$, height $61.8 \mathrm{~mm}$, depth $57.8 \mathrm{~mm}$ ) that can be opened by a foot pedal and place it on the square pegboard $(8 \times 8 \mathrm{~cm})$ with $14 \times 14$ pins according to the pattern hanging in the very back of the Pelvic Trainer. The beads have to be picked and placed in a predefined order, namely from the upper

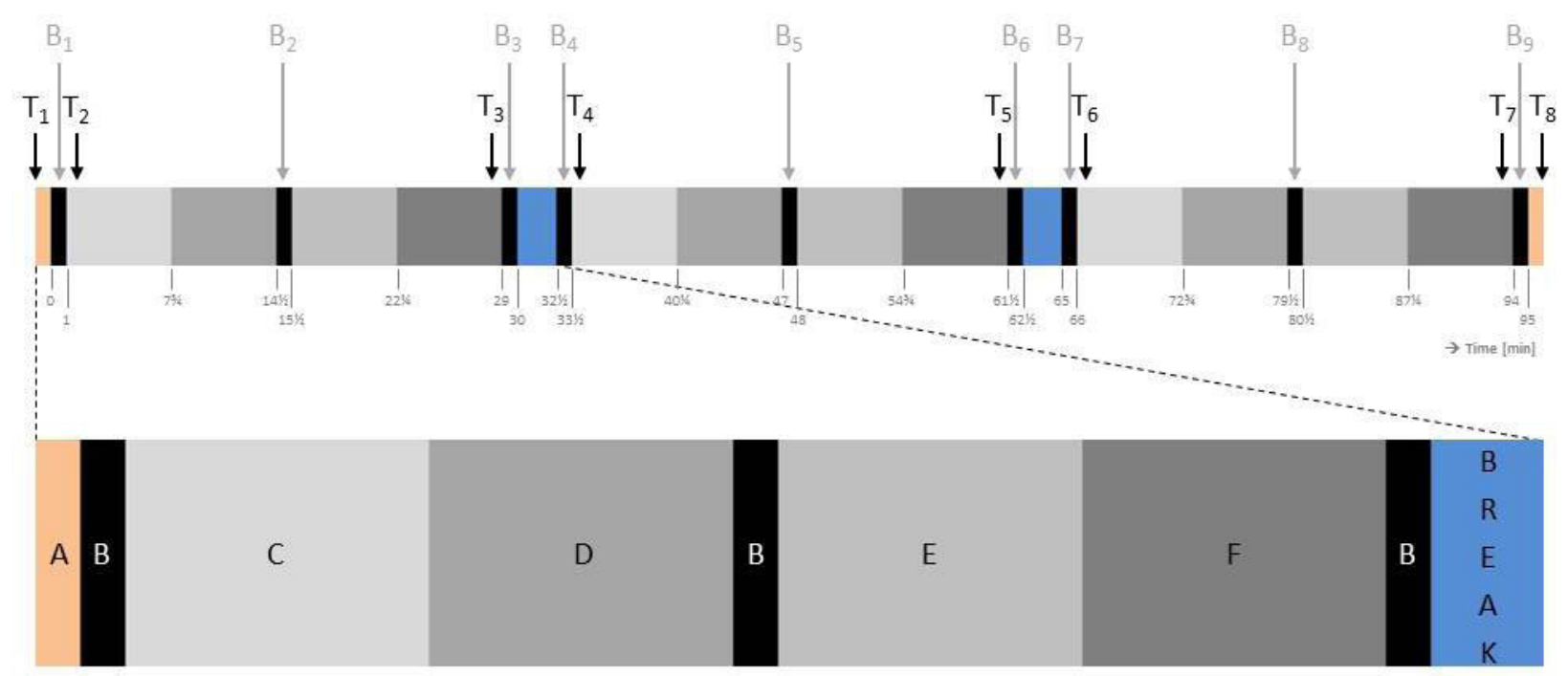

Figure 3 The 90+5 min time course of tasks including work breaks; for the condition without breaks, the blue blocks disappear. Each block and letter relates to a task, including the hot-wire (A), peg-transfer (B), pick-and-place (C), pick-and-tighten (D), pickand-thread $(E)$ and pull-and-stick task $(F)$. The arrows indicate the time points of recordings of rating of perceived discomfort $\left(\mathrm{T}_{1-8}\right)$ and recordings of muscle activity, upper body posture and heart rate $\left(\mathrm{B}_{1-9}\right)$ during the peg-transfer task $(\mathrm{B})$. 
left to the lower right corner. The box remains open for 5 $\mathrm{s}$ after operating the foot pedal.

The pick-and-tighten task is performed bimanually with a $33 \mathrm{~cm}$ long forceps with 1:2 teeth (RS225-595, RUDOLF Medical GmbH \& Co. KG) in the right hand and a $33 \mathrm{~cm}$ long forceps without teeth (33321 KW, KARL STORZ SE \& Co. KG) in the left hand and will last up to $6.75 \mathrm{~min}$. The participant has to take a red rubber band (diameter $160 \mathrm{~mm}$, thickness $1 \mathrm{~mm}$, width $5 \mathrm{~mm}$ ) with one of both laparoscopic instruments and stretch it over two wooden dowels (diameter $10 \mathrm{~mm}$, height $32 \mathrm{~mm}$ ). The task set-up contains eight dowels, positioned in a radius of $102.1 \mathrm{~mm}$ with a space of $65 \mathrm{~mm}$ in between consecutive dowels. When stretching a rubber band over two dowels, two have to be skipped, which makes the distance over which the rubber band has to be tightened $165 \mathrm{~mm}$. In total, eight rubber bands have to be picked from the lower left corner of the task set-up consecutively and tightened over pairs of dowels by starting at the top dowel (ie, 0 o'clock) and continuing clockwise. When this is finished, the rubber bands will be taken down to the dowel lower right corner of the task set-up, after which the picking and tightening will start again from the top dowel (ie, 0 o'clock) but now counterclockwise. When this is finished again, the rubber bands will be taken down to the lower left corner of the task set-up and the task is continued from the start.

The pick-and-thread task is performed bimanually with a $33 \mathrm{~cm}$ long $\mathrm{KOH}$ macro needle holder (26173 KAR, KARL STORZ SE \& Co. KG) in the right hand and a $33 \mathrm{~cm}$ long forceps without teeth (33321 KW, KARL STORZ SE \& Co. KG,) in the left hand and will last up to $6.75 \mathrm{~min}$. The participant will pick a bead with the instrument in the left hand from the wooden box, which is opened using the foot pedal, and thread it onto a half-circle, round, blunt needle that is connected to a $45 \mathrm{~cm}$ thread (Type RB6144, Mersilene, Ethicon US, LLC) that is held by the instrument in the right hand. Each bead that is placed over the blunt needle should be pulled onto the thread before the next bead is taken. There are no prescriptions for a colour code of the threaded beads.

The pull-and-stick task is performed bimanually with a $33 \mathrm{~cm}$ long forceps with 1:2 teeth (RS225-595, RUDOLF Medical GmbH \& Co. KG) in the right hand and a $33 \mathrm{~cm}$ long forceps without teeth (33321 KW, KARL STORZ SE \& Co. KG) in the left hand and will last up to $6.75 \mathrm{~min}$. The participant has to take off self-adhesive, round, paper marking points (diameter $8 \mathrm{~mm}$ ) from a stapling paper $(9 \times 5$ lanes, $107.5 \times 55.0 \mathrm{~mm})$ on the upper part of the task set-up and stick them on an empty paper on the lower part of the task set-up $(107.5 \times 55.0 \mathrm{~mm})$. There is no prescription in which order the marking points should be pulled and stuck.

\section{Data collection}

Baseline demographics, including current primary job description, total laparoscopic experience in years, total number of laparoscopies carried out to date, current average number of laparoscopies performed per week, age, gender, body height, body weight, smoking status, and sport hours per week will be captured during the familiarisation trial (see demographics in table 1). Additionally, participants will fill out the German version ${ }^{43}$ of the standardised Nordic Musculoskeletal Questionnaire ${ }^{44}$ (NMQ). The standardised NMQ is developed in English and has shown a test-retest validity of at least $77 \%$ and an inter-rater percentage disagreement reflecting reliability of at least $0.87 .^{44}$ Although no real validation study has been set-up for the NMQ this questionnaire has been accepted and is still frequently used in various occupational settings to identify the prevalence of work-related musculoskeletal symptoms. ${ }^{45-48}$

While the familiarisation trial will be supervised by one study leader, two study leaders are needed for the three experimental conditions. One of them will be responsible for the participant and the rapid change of tasks in the Pelvic Trainer; the other will be responsible for monitoring the quality and executing and recording both the continuous and discontinuous measurements.

\section{Primary outcome}

Rating of perceived discomfort (RPD)

Data of RPD will be collected on eight different time points: directly before and after the complete simulation and shortly after start and shortly before end of each 30 min block by one single item (see figure 3 ). An 11-point NRS will be used for the RPD running from 0 (no discomfort at all) to 10 (maximum imaginable discomfort). ${ }^{49}$ For reporting musculoskeletal pain, the English version of the NRS has shown excellent reliability (ICC of 0.95) and good to excellent validity with Pearson correlation coefficients with the VAS and verbal rating scale of 0.94 and 0.93 , respectively. ${ }^{50}$ Although the 11-point NRS has not been validated for reporting musculoskeletal discomfort, we assume it is an appropriate method to assess our primary outcome RPD.

Participants will be asked whether they experience discomfort; if the answer is yes, they will be asked how much discomfort they experience and in which body region(s) according to the body map of Corlett ${ }^{51}$ (cf. figure 4). The concept of RPD, the response scale (ie, VAS), and how discomfort is asked for nine times during each of the experimental conditions (figure 4) is explained in the familiarisation trial, which takes place on a separate day prior to the experiment.

\section{Secondary outcomes}

\section{Performance}

Performance of the hot-wire task will be tracked as the relative part of the total time $(\%)$ the hot wire was not touched during the first repetition prior to the simulation $\left(\mathrm{A}_{1}\right)$ and the second repetition directly after the simulation $\left(\mathrm{A}_{2}\right)$. For the peg-transfer, performance will equal the total amount of pegs transferred within the provided $60 \mathrm{~s}$ timeframe. The first $\left(\mathrm{B}_{1}\right)$ and last $\left(\mathrm{B}_{9}\right)$ repetitions will be used for statistical analysis. 

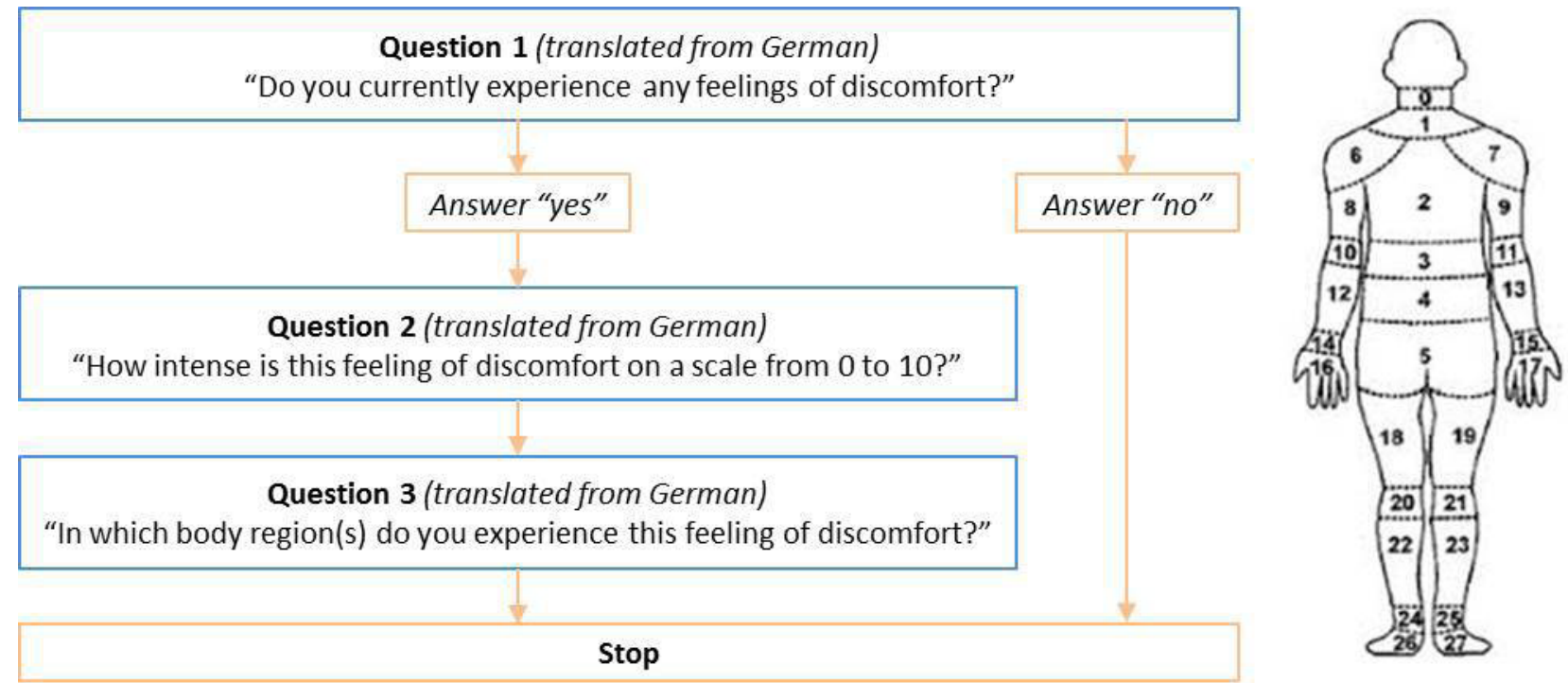

Figure 4 Left: guiding questions to ask the subject's perceived feeling of discomfort. Right: body map adapted from Corlett ${ }^{51}$ to define the body regions.

\section{Muscular activity and muscular fatigue}

Muscular activity will be recorded continuously using surface electromyography (EMG), for which two electrodes will be placed over each muscle belly, separated by an inter-electrode distance of $25 \mathrm{~mm}$. EMG of the following muscles will be recorded: $\mathrm{Mm}$. erector spinae longissimus lumbalis (bilateral), trapezius descendens (bilateral), deltoid acromialis (right side), extensor digitorum (right side) and flexor carpi radialis (right side). From the EMG signals, the root-mean-square (RMS) and median power frequency (MPF) can be calculated. The RMS will be expressed as a per cent of the RMS during the MVC, that is, maximal voluntary electrical activity (\%MVE). MVC is performed for each muscle in twofold prior to each of the three experimental conditions. The MPF will be expressed in Hertz $(\mathrm{Hz})$. In all cases, we will evaluate the static, median and peak level of RMS for each muscle, which can be determined by the 10th, 50th and 90th percentiles of the RMS signal over a specific recording period. For each of the muscles, the average of the 10th, 50th and 90th percentiles of RMS for the first $\left(B_{1}\right)$, third $\left(B_{3}\right)$, fourth $\left(B_{4}\right)$, sixth $\left(B_{6}\right)$, seventh $\left(B_{7}\right)$ and ninth $\left(\mathrm{B}_{9}\right)$ peg-transfer task will be calculated (cf. figure 3). If the quality of the data is sufficient, we may be able to evaluate the development of localised muscular fatigue, for which the change (ie, slope expressed as change per minute) across the median RMS ( $\mathrm{RMS}_{\mathrm{SLOPE}}$ $(\% \mathrm{MVE} / \mathrm{min}))$ and MPF $\left(\mathrm{MPF}_{\mathrm{SLOPE}}(\mathrm{Hz} / \mathrm{min})\right)$ will be calculated over the third $\left(\mathrm{B}_{3}\right)$, sixth $\left(\mathrm{B}_{6}\right)$ and ninth $\left(\mathrm{B}_{9}\right)$ peg-transfer task (cf. figure 3 ) and be plotted against each other in joint analyses of the EMG spectrum and amplitude (JASA). ${ }^{52}$

\section{Upper body posture}

Motion of the upper body will be recorded using position sensors placed on the forehead, thoracic vertebrae $\mathrm{T} 1$ and T10, and lumbar vertebrae L1 and L5. The difference in the flexion angles with respect to the absolute perpendicular (gravitational axis) of three pairs of sensors will be used to calculate the cervical lordosis (forehead-T1), thoracic kyphosis (T1-T10) and lumbar lordosis (L1-L5). The difference in the lateral flexion angles with respect to the absolute perpendicular of one pair of sensors will be used to calculate the neck lateral flexion angle (forehead-T1). The lateral flexion angle with respect to the absolute perpendicular of one sensor will be used to determine the trunk lateral flexion angle (T10). The average of the five angles for the first $\left(B_{1}\right)$, third $\left(\mathrm{B}_{3}\right)$, fourth $\left(\mathrm{B}_{4}\right)$, sixth $\left(\mathrm{B}_{6}\right)$, seventh $\left(\mathrm{B}_{7}\right)$ and ninth $\left(\mathrm{B}_{9}\right)$ peg-transfer task will be calculated (cf. figure 3).

\section{Heart rate and heart rate variability}

$\mathrm{HR}$, expressed in Hertz $(\mathrm{Hz})$, will be continuously recorded using ECG, for which two electrodes will be placed $\sim 5 \mathrm{~cm}$ cranial and $\sim 3 \mathrm{~cm}$ left-lateral from the distal end of the sternum and over the anterior to mid-axillary line at the fifth left rib. Several HRV indices ${ }^{53-55}$ will be calculated from the ECG signal's time domain, including interbeat intervals (IBIs), SD of the IBIs (SDNN) and root mean squared successive differences between IBIs (RMSSD). All three HRV indices showed good reliability among smaller sample sizes (ICC over 0.7 ) ${ }^{53}$ The median HR, IBI, SDNN and RMSSD for the first $\left(B_{1}\right)$, third $\left(B_{3}\right)$, fourth $\left(\mathrm{B}_{4}\right)$, sixth $\left(\mathrm{B}_{6}\right)$, seventh $\left(\mathrm{B}_{7}\right)$ and ninth $\left(\mathrm{B}_{9}\right)$ pegtransfer task will be calculated (cf. figure 3 ) as well as for the breaks to get an indication whether the active work break protocol has really been active compared with the passive work break protocol.

The signals of EMG, position sensors and ECG will be analysed and stored using a combined data analyser and logger (PS11-UD, THUMEDI GmbH \& Co. KG, Thum, Germany). The EMG signals will be sampled at $4096 \mathrm{~Hz}$ with an overall common-mode rejection ratio of $>96 \mathrm{~dB}$, an overall effective sum of noise of $<0.8 \mu \mathrm{V}$, and will be 
analysed in the frequency domain. The position sensors will be sampled at $4096 \mathrm{~Hz}$ with a resolution of $0.1^{\circ}$ and maximal measurement error of $0.3^{\circ}$, and will be analysed in the time domain. The ECG signals will be sampled at $1000 \mathrm{~Hz}$ and analysed in the time domain.

\section{Workload}

After each experimental condition, participants will fill out the National Aeronautics and Space Administration Task Load Index (NASA-TLX) to assess mental demand, physical demand, temporal demand, own performance, effort and frustration on a scale from 0 to 100 for each of the six tasks performed. ${ }^{56}$ The English version of the NASA-TLX has a high overall validity (0.86 Pearson correlation $)^{56}$ and excellent convergent validity with two other workload instruments (0.98 Pearson correlation $)^{57}$ and its German translated version has been validated and used in studies as well. ${ }^{58} 59$ The overall workload will be assessed by the unweighted average of all six dimensions and all six tasks, ${ }^{60} 61$ which may range between 0 (low subjective workload) and 100 (high subjective workload).

\section{Subjective evaluation}

After both intervention conditions, participants will fill out a self-developed questionnaire evaluating the conducted passive or active work breaks (see online supplemental material 4). The questionnaire contains seven questions: one about recovered body parts with multiple answer options; five about work break content, frequency, duration, performance and concentration using a five-point Likert scale; one about the likelihood of carrying out breaks on own initiative using a $100 \mathrm{~mm}$ VAS. Five-point and seven-point Likert scales showed to have comparable mean and variance values after rescaling. ${ }^{62}$ The reason that we used five-point Likert scales is because they would be generally better comprehensible and therefore more accurate, ${ }^{63}$ valid and reliable ${ }^{64} 65$ when compared with more-point Likert scales. We decided to use a $100 \mathrm{~mm}$ VAS for evaluating how likely it is the surgeon will implement active or passive intraoperative work break, because the VAS applies a continuous response format, so that the surgeon is not restricted to a predetermined set of potential responses. ${ }^{66}$ Although the $100 \mathrm{~mm}$ VAS has not been validated for the current evaluation question, it has shown excellent reliability (ICC 0.97 ) and good to excellent validity (Pearson correlation of 0.94 with 11-point NRS) when assessing musculoskeletal pain. ${ }^{50}$

\section{Statistical analysis}

An overview of the primary and secondary outcomes is provided in table 2 , including a description of the time points per outcome.

The primary outcome RPD and the secondary outcomes performance $_{\text {HOT_WIRE }}$ and performance ${ }_{\mathrm{PEG}}$ will be statistically tested using the generalised estimating equations $(\mathrm{GEE})^{67}$ with condition (three levels: no vs passive vs active work breaks) and time (two levels: $\mathrm{T}_{1} / \mathrm{A}_{1} / \mathrm{B}_{1}$ vs $\mathrm{T}_{8} / \mathrm{A}_{2} / \mathrm{B}_{9}$ ) as within-subject factors. For significant main or interaction effects, we will perform post hoc pairwise comparisons using the Šidák correction. ${ }^{68}$

The secondary outcomes RMS $\mathrm{STATIC}_{\text {, }} \mathrm{RMS}_{\text {MEDIAN }}, \mathrm{RMS}_{\text {PEAK}}$, angle $_{\text {MEDIAN }}$, HR, IBI, SDNN and RMSSD will be analysed using the GEE with condition (three levels: no vs passive vs active work breaks) and time (six levels: $\mathbf{B}_{1}, \mathbf{B}_{3}, \mathbf{B}_{4}, \mathbf{B}_{6}$, $\mathrm{B}_{7}, \mathrm{~B}_{9}$ ) as the within-subject factors. For significant main or interaction effects, we will perform post hoc pairwise comparisons using the Šidák correction. The secondary

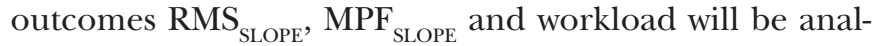
ysed using the GEE with condition (three levels: no vs passive vs active work breaks) as the within-subject factor. For significant main effects, we will perform post hoc pairwise comparisons using the Šidák correction. The six items of the evaluation questionnaire using a NRS or a VAS will be statistically tested using the GEE with condition (two levels: passive vs active work breaks) as the within-subject variable.

Although the order of conditions is randomised, we did not employ a full-factorial design, which means the order of the conditions (ie, order 1 to 6 ; cf. figure 1 ) will be included as a confounding variable in GEE.

The demographic outcomes as well as the one item of the evaluation questionnaire having multiple answer options will be analysed using descriptive statistics by presenting mean (SD) or median (IQR) according to the statistical distribution.

\section{Subgroups analyses}

This study is not designed to detect differences in potential subgroups within the study population. Therefore, we will follow an exploratory approach and be hypothesis generating rather than follow a confirmatory approach and be hypothesis testing. The aim of the exploratory subgroup analysis is to clarify potential heterogeneity of the effect of work breaks on the primary and secondary outcomes by splitting the participant data into subgroups. ${ }^{69}$ We hereby take account of the lack of power to allow for significant results and rather use the results for future study data synthesis. ${ }^{70}$ Although Burke $e t a l^{1}$ recommended not carrying out more than two subgroup analyses because it increases the likelihood of finding false positives, we decided to carry out more since we follow an exploratory approach in order to generate further research hypotheses. There are several risk factors to be identified for subgroup analyses that have been shown to be associated with the occurrence of WRMSD,${ }^{72}$ including working posture, work experience, age, gender, stressful working conditions, daily working hours and repetitive and forceful movements. From these risk factors, we considered gender and age as relevant indicators for our exploratory subgroup analyses for their potential influence on the effect of the intervention (ie, work breaks) on the study outcomes. We complemented the subgroup analyses with selected items of the NASA-TLX.

- Gender: male versus female.

- The literature is not unanimous as to whether gender plays a significant role as a risk factor for 
Table 2 Description of the dependent variables (outcomes) that will be statistically tested

\begin{tabular}{|c|c|c|c|}
\hline Domain & Outcome & Calculation & Unit \\
\hline \multicolumn{4}{|c|}{ Primary outcome } \\
\hline $\begin{array}{l}\text { Rating of } \\
\text { perceived } \\
\text { discomfort }\end{array}$ & RPD & Rating at time points $T_{2}$ and $T_{7}$ & $(0-10)$ \\
\hline
\end{tabular}

\section{Secondary outcomes}

\begin{tabular}{|c|c|c|c|}
\hline \multirow[t]{2}{*}{ Performance } & Performanc $_{\text {HOT_WIRE }}$ & $\begin{array}{l}\text { Relative time the ring did not touch the wire before }\left(A_{1}\right) \text { and after }\left(A_{2}\right) \text { each } \\
\text { condition }\end{array}$ & (\%) \\
\hline & Performance $_{\mathrm{PEG}}$ & $\begin{array}{l}\text { Number of transferred pegs / } 60 \text { s in the first }\left(B_{1}\right) \text { and ninth }\left(B_{9}\right) \text { peg-transfer } \\
\text { task }\end{array}$ & (\#) \\
\hline \multirow[t]{2}{*}{$\begin{array}{l}\text { Muscular } \\
\text { activity }\end{array}$} & $\mathrm{RMS}_{\text {STATIC }}$ * & $\begin{array}{l}\text { 10th percentile muscle activity in the first }\left(B_{1}\right) \text {, third }\left(B_{3}\right) \text {, fourth }\left(B_{4}\right) \text {, sixth }\left(B_{6}\right) \text {, } \\
\text { seventh }\left(B_{7}\right) \text { and ninth }\left(B_{9}\right) \text { peg-transfer task }\end{array}$ & (\%MVE) \\
\hline & $\mathrm{RMS}_{\text {MEDIAN }}{ }^{*}$ & $\begin{array}{l}\text { 50th percentile muscle activity in the first }\left(B_{1}\right) \text {, third }\left(B_{3}\right) \text {, fourth }\left(B_{4}\right) \text {, sixth }\left(B_{6}\right) \text {, } \\
\text { seventh }\left(B_{7}\right) \text { and ninth }\left(B_{9}\right) \text { peg-transfer task }\end{array}$ & (\%MVE) \\
\hline \multirow[t]{2}{*}{$\begin{array}{l}\text { Muscular } \\
\text { fatigue }\end{array}$} & $\mathrm{RMS}_{\text {SLOPE }}{ }^{*}$ & $\begin{array}{l}\text { Slope using the median RMS of the third }\left(B_{3}\right) \text {, sixth }\left(B_{6}\right) \text { and ninth }\left(B_{9}\right) \text { peg- } \\
\text { transfer task }\end{array}$ & (\%MVE/min) \\
\hline & MPF $_{\text {SLOPE }}{ }^{*}$ & $\begin{array}{l}\text { Slope using the MPF of the third }\left(B_{3}\right) \text {, sixth }\left(B_{6}\right) \text { and ninth }\left(B_{9}\right) \text { peg-transfer } \\
\text { task }\end{array}$ & $(\mathrm{Hz} / \mathrm{min})$ \\
\hline \multirow[t]{3}{*}{$\begin{array}{l}\text { Heart rate } \\
\text { variability }\end{array}$} & $\mid \mathrm{BI}$ & $\begin{array}{l}\text { Median IBI during the first }\left(B_{1}\right) \text {, third }\left(B_{3}\right) \text {, fourth }\left(B_{4}\right) \text {, sixth }\left(B_{6}\right) \text {, seventh }\left(B_{7}\right) \\
\text { and ninth }\left(B_{9}\right) \text { peg-transfer task }\end{array}$ & (ms) \\
\hline & SDNN & $\begin{array}{l}\text { Median SDNN during the first }\left(B_{1}\right) \text {, third }\left(B_{3}\right) \text {, fourth }\left(B_{4}\right) \text {, sixth }\left(B_{6}\right) \text {, seventh } \\
\left(B_{7}\right) \text { and ninth }\left(B_{9}\right) \text { peg-transfer task }\end{array}$ & (ms) \\
\hline & RMSSD & $\begin{array}{l}\text { Median RMSSD during the first }\left(B_{1}\right) \text {, third }\left(B_{3}\right) \text {, fourth }\left(B_{4}\right) \text {, sixth }\left(B_{6}\right) \text {, seventh } \\
\left(B_{7}\right) \text { and ninth }\left(B_{9}\right) \text { peg-transfer task }\end{array}$ & (ms) \\
\hline Workload & Workload & Unweighted average over all tasks and domains & $(0-100)$ \\
\hline
\end{tabular}

Symbols used in the description of the calculation-column (ie, $T_{1}, T_{6}, B_{1}, B_{3}, B_{4}, B_{6}, B_{7}, B_{9}$ ) are indicated in figure 3 .

*The seven muscles are as follows: erector spinae left and right, trapezius descendens left and right, deltoid medialis right, extensor digitorum right, flexor carpi radialis right.

†This outcome is tested for five angles: cervical lordosis, thoracic kyphosis, lumbar lordosis, neck lateral flexion, trunk lateral flexion. $\mathrm{HR}$, heart rate; IBI, interbeat interval; MPF, median power frequency; RMS, root mean square; RPD, rating of perceived discomfort.

the development of WRMSD. Some studies show a significant association between gender and WMRSD ${ }^{72-74}$ whereas others do not, ${ }^{75}$ although the vulnerability varies between men and women depending on the affected body site. ${ }^{746}$

- Age: study population divided into two groups based on the median of the overall study population (ie, group 1:Smedian; group 2:>median).

- Recent reports and studies highlight the increasing prevalence of WRMSD with increasing age ${ }^{77}$ and some even show a significant association between age and prevalence of WRMSD. ${ }^{75} 7678$

- Previous or current episodes of musculoskeletal symptoms: study population divided into two groups based on whether participants at any time in their life had any ache, discomfort or pain in one or more body areas (question as part of the NMQ; that is, group 1: yes; group 2: no).
- A recent study among nursing personnel showed that a previous episode of low back pain (LBP) was associated (OR of 4.31) with disabling LBP. ${ }^{79}$

Dealing with missing data

In case of missing data in the performance, muscle activity, postural and HR data, the missing value will not be filled. In case of the NASA-TLX items, missing values will be filled using the single imputation method of the most frequent value. ${ }^{80}$ Although this simple technique is likely to cause biased overall estimates, ${ }^{81} 82$ we consider this likelihood small, since we check this NASA-TLX questionnaire directly after completion.

\section{Data management and confidentiality}

The physical collected and digitally recorded data will be numerically pseudonymised by assigning a randomly generated, two-digit identification number to the 
examined participant to maintain confidentiality. The physical collected data forms will be stored in locked cabinets of the institute of occupational and social medicine and health services research (IASV) in areas with limited access. The digitally recorded data will be saved on a separate server of the IASV. A decoding list together with written informed consent forms of the participants will be stored in separate locked cabinets of the IASV in areas with limited access. Only the principal investigator (TL) and some other researchers (BS, MAR) directly involved in the study can get permission to access the decoding list and the physical and digital data.

All data will be stored for a period of 10 years after publication of the study results. After 10 years, the destruction of the data in paper form is carried out by means of the disposal boxes for data protection at the UKT, and the destruction of the data in electronic form is carried out by means of transferring the data off the memory cards of the devices (ie, measurement equipment, laptops and personal computers.

\section{Data monitoring and quality assurance}

The progress of the study will be monitored by the principal investigator (TL), who is also responsible for reporting to the (preliminary) data to the main collaborator, the DOG of the UKT.

The occurrence of adverse events that could be related to the work-break intervention will be monitored and assessed by the researcher that is present during the laparoscopic simulations at the laboratory. Related to the intervention are those adverse events that occur after the participant started to receive the study intervention. The expectation that adverse events occur is very small; therefore, harms will be part of routine monitoring and not categorised as primary or secondary outcome.

Safety standards of the devices and measurement equipment that will be used are documented in declarations of conformity that were received at the time of purchase of the devices and equipment.

\section{Patient and public involvement}

Patients and the public were not involved in the design, or conduct, or reporting, or dissemination plans of this trial.

\section{ETHICS AND DISSEMINATION}

\section{Research ethical approval}

The study and all study-related documents were designed following the principles formulated in the current version of the Declaration of Helsinki. ${ }^{83} \mathrm{~A}$ final approval of the study design including suggested amendments by the responsible local ethical committee (no 618/2018BO2) of the Medical Faculty of the University and UKT was received in February 2019 (see online supplemental material 5).

\section{Dissemination}

Abstracts of the study protocol and (preliminary) study results may be submitted for a presentation to relevant scientific symposia and conferences in the field of occupational ergonomics and human factors, which can be either local (Research Colloquium of the Medical Faculty of Tübingen), national (GfA, DGAUM, FAP) or international (PREMUS, IEA, ICOH). The study will result in three results papers that will be submitted to, for example, one of the following international, peer-reviewed journals: Annals of Surgery, Surgical Endoscopy, and International Journal of Surgery. In case subjects wish to be informed about the results of the study, they will receive the primary outcome paper by email.

Acknowledgements The authors would like to thank physiotherapist Georg Haupt for his support in developing the exercise protocol for the active work breaks and Nadine Badie, Julia Gabriel and Xaver Thalhofer for their support in data collection. The study protocol has been presented as a poster at an international conference (PREMUS 2019, Bologna, Italy) and as a presentation at a national conference (GfA 2020, Berlin, Germany).

Contributors Principal investigator of the study is TL. The idea and concept of the study were developed by TL, BS and MAR. Preparation of the simulation material was all prepared by RS and RB. TL drafted this study protocol and all other authors (BS, MAR, RS, BK, RB) revised the manuscript and approved the final version. TL and RB will be involved in the data collection. TL will be responsible for the data analysis and for writing the findings in consequent results manuscripts.

Funding This work was partially supported by a personal intramural fortüne grant (TL) from the Junior Academy of the Faculty of Medicine of the University of Tübingen (Germany), with grant number (2480-1-0). The remainder of the work of the Institute of Occupational and Social Medicine and Health Services Research was financially supported by an unrestricted grant of the employers association of the metal and electrical industry Baden-Württemberg (Südwestmetall; grant number N/A).

\section{Competing interests None declared.}

Patient and public involvement statement Patients and the public were not involved in the design, or conduct, or reporting, or dissemination plans of this trial.

Patient consent for publication Not required.

Provenance and peer review Not commissioned; externally peer reviewed.

Supplemental material This content has been supplied by the author(s). It has not been vetted by BMJ Publishing Group Limited (BMJ) and may not have been peer-reviewed. Any opinions or recommendations discussed are solely those of the author(s) and are not endorsed by BMJ. BMJ disclaims all liability and responsibility arising from any reliance placed on the content. Where the content includes any translated material, BMJ does not warrant the accuracy and reliability of the translations (including but not limited to local regulations, clinical guidelines, terminology, drug names and drug dosages), and is not responsible for any error and/or omissions arising from translation and adaptation or otherwise.

Open access This is an open access article distributed in accordance with the Creative Commons Attribution Non Commercial (CC BY-NC 4.0) license, which permits others to distribute, remix, adapt, build upon this work non-commercially, and license their derivative works on different terms, provided the original work is properly cited, appropriate credit is given, any changes made indicated, and the use is non-commercial. See: http://creativecommons.org/licenses/by-nc/4.0/.

ORCID iD

Tessy Luger http://orcid.org/0000-0001-5718-251X

\section{REFERENCES}

1 Palmer R. Instrumentation et technique de la coelioscopie gynécologique [Instrumentation and technique of gynaecological laparoscopy]. Gynecol Obstet 1947;46:420-31.

2 Yi X, Chen S, Wang W, et al. A systematic review and meta-analysis of laparoscopic and open distal pancreatectomy of nonductal Adenocarcinomatous pancreatic tumor (NDACPT) in the pancreatic body and tail. Surg Laparosc Endosc Percutan Tech 2017;27:206-19.

3 Tan S, Wu G, Zhuang Q, et al. Laparoscopic versus open repair for perforated peptic ulcer: a meta analysis of randomized controlled trials. Int J Surg 2016;33 Pt A:124-32. 
4 Li H, Zheng J, Cai J-Y, et al. Laparoscopic VS open hepatectomy for hepatolithiasis: An updated systematic review and meta-analysis. World J Gastroenterol 2017;23:7791-806.

5 Ridtitid W, Coté GA, Leung W, et al. Prevalence and risk factors for musculoskeletal injuries related to endoscopy. Gastrointest Endosc 2015;81:294-302.

6 Berguer R, Rab GT, Abu-Ghaida H, et al. A comparison of surgeons' posture during laparoscopic and open surgical procedures. Surg Endosc 1997;11:139-42.

7 Nguyen NT, Ho HS, Smith WD, et al. An ergonomic evaluation of surgeons' axial skeletal and upper extremity movements during laparoscopic and open surgery. Am J Surg 2001;182:720-4.

8 da Costa BR, Vieira ER. Risk factors for work-related musculoskeletal disorders: a systematic review of recent longitudinal studies. Am J Ind Med 2010;53:285-323.

9 Kozak A, Schedlbauer G, Wirth T, et al. Association between work-related biomechanical risk factors and the occurrence of carpal tunnel syndrome: an overview of systematic reviews and a meta-analysis of current research. BMC Musculoskelet Disord 2015;16:231.

10 Dabholkar T, Yardi S, Dabholkar Y. Prevalence of work-related musculoskeletal symptoms in surgeons performing minimally invasive surgery: a review of literature. Int Surg J 2016:1028-34.

11 Tjiam IM, Goossens RH, Schout BM, et al. Ergonomics in endourology and laparoscopy: an overview of musculoskeletal problems in urology. $J$ Endourol 2014;28:605-11.

12 Stomberg MW, Tronstad S-E, Hedberg K, et al. Work-Related musculoskeletal disorders when performing laparoscopic surgery. Surg Laparosc Endosc Percutan Tech 2010;20:49-53.

13 Op de Beeck R, Hermans V. Research on work-related low back disorders. Brussels, Belgium: European Agendcy for Safety and Health at Work, 2000.

14 Matern U, Eichenlaub M, Waller P, et al. Mis instruments. An experimental comparison of various ergonomic handles and their design. Surg Endosc 1999;13:756-62.

15 Matern U, Kuttler G, Giebmeyer C, et al. Ergonomic aspects of five different types of laparoscopic instrument handles under dynamic conditions with respect to specific laparoscopic tasks: an electromyographic-based study. Surg Endosc 2004;18:1231-41.

16 Steinhilber B, Reiff F, Seibt R, et al. Ergonomic benefits from a laparoscopic instrument with rotatable handle piece depend on the area of the operating field and working height. Hum Factors 2017;59:1048-65.

17 Steinhilber B, Seibt R, Reiff F, et al. Effect of a laparoscopic instrument with rotatable handle piece on biomechanical stress during laparoscopic procedures. Surg Endosc 2016;30:78-88.

18 Trejo AE, Doné KN, DiMartino AA, et al. Articulating vs. conventional laparoscopic grasping tools - surgeons' opinions. Int J Ind Ergon 2006;36:25-35.

19 Steinhilber B, Hoffmann S, Karlovic K, et al. Development of an arm support system to improve Ergonomics in laparoscopic surgery: study design and provisional results. Surg Endosc 2015;29:2851-8

20 Karlovic K, Pfeffer S, Maier T, et al. Analysis of body-, arm- and hand-posture and the human-machine-interaction when using an arm-support-device for laproscopic surgery - results of an evaluation in laboratory setting. Glob Surg 2016;2:84-7.

21 Albayrak A, van Veelen MA, Prins JF, et al. A newly designed ergonomic body support for surgeons. Surg Endosc 2007;21:1835-40.

22 Nishimoto W, Kawahira H, Shimomura Y, et al. A standing posture support device that reduces laparoscopic surgeons occupational lower limb stress. Minim Invasive Ther Allied Technol 2019;28:151-6.

23 Luger T, Maher CG, Rieger MA, et al. Work-break schedules for preventing musculoskeletal symptoms and disorders in healthy workers. Cochrane Database Syst Rev 2019;7:CD012886.

24 Schmidt J, Rothmund R, Michaelis M, et al. Welche muskuloskelettalen Beschwerden und arbeitsorganisatorische Maßnahmen zu ihrer Reduktion berichtet das chirurgische Personal in der Gynäkologie? Studiendesign einer standardisierten Befragung mit Fokus auf laparoskopische Eingriffe [What musculoskeletal complaints and work organisation measures to reduce them are reported by surgical staff in gynaecology? Study design of a standardized survey with focus on laparoscopic interventions. 63. Dortmund, Germany: Frühjahrskongress 2017 der Gesellschaft für Arbeitswissenschaft eV, 2017

25 Steinhilber B, Karle E, Schmidt J, et al. Prevalence of musculoskeletal complaints in minimal invasive surgery. 10th International Conference on the prevention of work-related musculoskeletal disorders. Italy,Bologna: PREMUS, 2019.
26 Engelmann C, Schneider M, Kirschbaum C, et al. Effects of intraoperative breaks on mental and somatic operator fatigue: a randomized clinical trial. Surg Endosc 2011;25:1245-50.

27 Park AE, Zahiri HR, Hallbeck MS, et al. Intraoperative "micro breaks" with targeted stretching enhance surgeon physical function and mental focus: A multicenter cohort study. Ann Surg 2017;265:340-6.

28 Dorion D, Darveau S. Do micropauses prevent surgeon's fatigue and loss of accuracy associated with prolonged surgery? an experimental prospective study. Ann Surg 2013;257:256-9.

29 Hallbeck MS, Lowndes BR, Bingener J, et al. The impact of intraoperative microbreaks with exercises on surgeons: a multicenter cohort study. Appl Ergon 2017;60:334-41.

30 Coleman Wood KA, Lowndes BR, Buus RJ, et al. Evidence-Based intraoperative microbreak activities for reducing musculoskeletal injuries in the operating room. Work 2018;60:649-59.

31 Abdelall ES, Lowndes BR, Abdelrahman AM, et al. Mini breaks, many benefits: development and pilot testing of an intraoperative microbreak stretch web-application for surgeons. Proc Hum Factors Ergon Soc Annu Meet 2018;62:1042-6.

32 Chan A-W, Tetzlaff JM, Altman DG, et al. Spirit 2013 statement: defining standard protocol items for clinical trials. Ann Intern Med 2013;158:200-7.

33 Chan A-W, Tetzlaff JM, Gøtzsche PC, et al. Spirit 2013 explanation and elaboration: guidance for protocols of clinical trials. $B M J$ 2013;346:e7586

34 Wenger L, Richardson C, Tsuda S. Retention of fundamentals of laparoscopic surgery (FLS) proficiency with a biannual mandatory training session. Surg Endosc 2015;29:810-4.

35 Henning RA, Jacques P, Kissel GV, et al. Frequent short rest breaks from computer work: effects on productivity and well-being at two field sites. Ergonomics 1997;40:78-91.

36 Shushan A, Mohamed H, Magos AL. How long does laparoscopic surgery really take? lessons learned from 1000 operative laparoscopies. Hum Reprod 1999;14:39-43.

37 Schoenfeld BJ. Is there a minimum intensity threshold for resistance training-induced hypertrophic adaptations? Sports Med 2013;43:1279-88.

38 Maxwell SE, Delaney HD. Designing experiments and analyzing data: a model comparison perspective. Second ed. London: Lawrence Erlbaum Associates Publishers, Inc, 2004.

39 Guo Y, Pandis N. Sample-size calculation for repeated-measures and longitudinal studies. Am J Orthod Dentofacial Orthop 2015;147:146-9.

40 Kadam P, Bhalerao S. Sample size calculation. Int J Ayurveda Res 2010;1:55-7.

41 Derossis AM, Fried GM, Abrahamowicz M, et al. Development of a model for training and evaluation of laparoscopic skills. Am J Surg 1998;175:482-7.

42 Peters JH, Fried GM, Swanstrom LL. Development and validation of a comprehensive program of education and assessment of the basic fundamentals of laparoscopic surgery. , 2004: 135, 21-7.

43 Caffier G, Steinberg U, Liebers F. Praxisorientiertes Methodeninventar Zur Belastungs- und Beanspruchungsbeurteilung Im Zusammenhang MIT arbeitsbedingten Muskel-Skelett-Erkrankunen. Dortmund / Berlin, Germany: Bundesanstalt für Arbeitsschutz und Arbeitsmedizin (BAUA), 1999.

44 Kuorinka I, Jonsson B, Kilbom A, et al. Standardised Nordic questionnaires for the analysis of musculoskeletal symptoms. Appl Ergon 1987;18:233-7.

45 Tariah HA, Nafai S, Alajmi M, et al. Work-Related musculoskeletal disorders in nurses working in the Kingdom of Saudi Arabia. Work 2020;65:421-8.

46 Momeni Z, Choobineh A, Razeghi M, et al. Work-Related musculoskeletal symptoms among agricultural workers: a crosssectional study in Iran. J Agromedicine 2020;57:1-10.

47 Vaghela N, Parekh S, Ganjiwale D, et al. Work-Related musculoskeletal disorder among surgeons in Gujarat. J Educ Health Promot 2019;8:248.

48 Grant KMK, Vo T, Tiong LU. The painful truth: work-related musculoskeletal disorders in Australian surgeons. Occup Med 2020;70:60-3.

49 McCaffery M, Beebe A. Pain: clinical manual for nursing practice. 353. St Louis, Missouri, US: C.V. Mosby Company, 1989.

50 Alghadir $\mathrm{AH}$, Anwer S, lqbal A, et al. Test-Retest reliability, validity, and minimum detectable change of visual analog, numerical rating, and verbal rating scales for measurement of osteoarthritic knee pain. $J$ Pain Res 2018;11:851-6.

51 Corlett EN. The evaluation of posture and its effects. In: Wilson JR, Corlett EN, eds. Evaluation of human work: a practical Ergonomics methodology. London: Taylor \& Francis, 1995. 
52 Luttmann A, Jäger M, Sökeland J, et al. Electromyographical study on surgeons in urology. II. Determination of muscular fatigue. Ergonomics 1996;39:298-313.

53 Hallman DM, Srinivasan D, Mathiassen SE. Short- and long-term reliability of heart rate variability indices during repetitive low-force work. Eur J Appl Physiol 2015;115:803-12.

54 Malik M, Bigger JT, Camm AJ, et al. Heart rate variability: standards of measurement, physiological interpretation, and clinical use. Eur Heart J 1996;17:354-81.

55 Shaffer F, Ginsberg JP. An overview of heart rate variability metrics and norms. Front Public Health 2017;5:258.

56 Hart SG, Staveland LE. Development of NASA-TLX(Task load index): results of emprical and theoretical research. Adv Psychol 1988;52:139-83.

57 Rubio S, Díaz E, Martín J, et al. Evaluation of subjective mental workload: a comparison of SWAT, NASA-TLX, and workload profile methods. Appl Psychol 2004;53:61-86.

58 Sepehr MM. Assessment of subjective mental workload using NASATask load index, 1988: 69-75.

59 Pfendler C. Vergleichende Bewertung des NASA-TLX Skala und der ZEIS-Skala bei der Erfassung von Lernprozessen [Comparative assessment of the NASA-TLX scale and the ZEIS scale in recording learning processes. 92. Wachtberg: Forschungsinstitut für Anthropotechnik.FAT Report Nr, 1991.

60 Hoonakker P, Carayon P, Gurses A, et al. Measuring workload of ICU nurses with a questionnaire survey: the NASA task load index (TLX). IIE Trans Healthc Syst Eng 2011;1:131-43.

61 Hendy KC, Hamilton KM, Landry LN. Measuring subjective workload: when is one scale better than many? Hum Factors 1993;35:579-601.

62 Dawes J. Do data characteristics change according to the number of scale points used? an experiment using 5-point, 7-point and 10-point scales. Int J Mark Res 2008;50:61-104.

63 Marton-Williams J. Questionnaire design. In: Worcester R, Downham J, eds. Consumer market research Handbook. London: McGraw-Hill Book Company, 1986.

64 Lissitz RW, Green SB. Effect of the number of scale points on reliability: a Monte Carlo approach. Journal of Applied Psychology 1975;60:10-13

65 McKelvie SJ. Graphic rating scales - How many categories? Br J Psychol 1978;69:185-202.

66 Klimek L, Bergmann K-C, Biedermann T, et al. Visual analogue scales (vas): measuring instruments for the documentation of symptoms and therapy monitoring in cases of allergic rhinitis in everyday health care: position paper of the German Society of Allergology (AeDA) and the German Society of allergy and clinical immunology (DGAKI), ENT section, in collaboration with the Working group on clinical immunology, Allergology and environmental medicine of the German Society of otorhinolaryngology, head and neck surgery (DGHNOKHC). Allergo J Int 2017;26:16-24.

67 Ma Y, Mazumdar M, Memtsoudis SG. Beyond repeated-measures analysis of variance: advanced statistical methods for the analysis of longitudinal data in anesthesia research. Reg Anesth Pain Med 2012;37:99-105.
$68 \mathrm{Kim} \mathrm{H}$-Y. Statistical notes for clinical researchers: post-hoc multiple comparisons. Restor Dent Endod 2015;40:172-6.

69 Deeks JJ, Higgins JPT, Altman DG. Chapter 9.6.2: What are subgroup analyses? In: Higgins JPT, Green S, eds. Cochrane Handbook for systematic reviews of interventions. Version 5.1.0 (updated March 2011). The Cochrane Collaboration, 2011. www. handbook.cochrane.org

70 Varadhan R, Segal JB, Boyd CM, et al. A framework for the analysis of heterogeneity of treatment effect in patient-centered outcomes research. J Clin Epidemiol 2013;66:818-25.

71 Burke JF, Sussman JB, Kent DM, et al. Three simple rules to ensure reasonably credible subgroup analyses. BMJ 2015;351:h5651.

72 Das D, Kumar A, Sharma M. A systematic review of work-related musculoskeletal disorders among handicraft workers. Int J Occup Saf Ergon 2020;26:55-70.

73 Coury HJCG, Porcatti IA, Alem MER, et al. Influence of gender on work-related musculoskeletal disorders in repetitive tasks. Int $\mathrm{J}$ Ind Ergon 2002;29:33-9.

74 Sharma R, Singh R. Work-Related musculoskeletal disorders, job stressors and gender responses in foundry industry. Int J Occup Saf Ergon 2014;20:363-73.

75 Oranye NO, Bennett J. Prevalence of work-related musculoskeletal and non-musculoskeletal injuries in health care workers: the implications for work disability management. Ergonomics 2018;61:355-66.

76 Macpherson RA, Lane TJ, Collie A, et al. Age, sex, and the changing disability burden of compensated work-related musculoskeletal disorders in Canada and Australia. BMC Public Health 2018;18:758.

77 de Kok J, Vroonhof P, Snijders J, et al. Work-Related musculoskeletal disorders: prevalence, costs and demographics in the EU: European risk Observatory report. Luxembourg: Publications Office of the European Union, 2019.

78 Cheung K, Szeto G, Lai GKB, et al. Prevalence of and factors associated with work-related musculoskeletal symptoms in nursing assistants working in nursing homes. Int J Environ Res Public Health 2018;15:e265.

79 Yoshimoto T, Oka H, Ishikawa S, et al. Factors associated with disabling low back pain among nursing personnel at a medical centre in Japan: a comparative cross-sectional survey. BMJ Open 2019;9:e032297.

80 Zhang Z. Missing data imputation: focusing on single imputation. Ann Transl Med 2016;4:9.

81 Glas CAW. Missing data. In: Peterson P, Tierney R, Baker E, eds. International encyclopedia of education. 3rd ed. Elsevier Science Ltd, 2010: 283-8.

82 Donders ART, van der Heijden GJMG, Stijnen T, et al. Review: a gentle introduction to imputation of missing values. $J$ Clin Epidemiol 2006;59:1087-91.

83 World Medical Association. World Medical association Declaration of Helsinki: ethical principles for medical research involving human subjects. JAMA 2013;310:2191-4. 